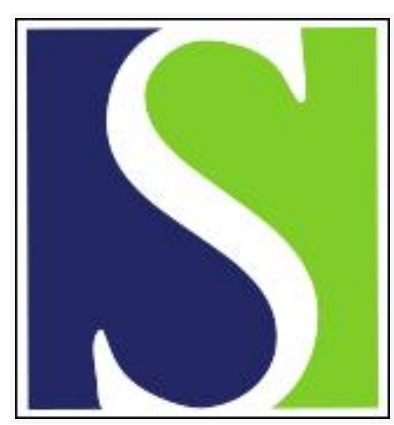

Scand J Work Environ Health 1988;14(4):239-245

https://doi.org/10.5271/sjweh.1926

Issue date: Aug 1988

The role of personal beliefs and social influences as determinants of respirator use among construction painters. by White MC, Baker EL, Larson MB, Wolford R

Affiliation: Occupational Health Program, Harvard School of Public Health, Boston, MA.

This article in PubMed: www.ncbi.nlm.nih.gov/pubmed/3175556

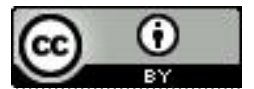




\title{
The role of personal beliefs and social influences as determinants of respirator use among construction painters
}

\author{
by Mary C White, ScD, ${ }^{1}$ Edward L Baker, MD, ${ }^{1}$ Marilyn B Larson, BA, ${ }^{2}$ Rodney Wolford, BA ${ }^{2}$
}

\begin{abstract}
WHITE MC, BAKER EL, LARSON MB, WOLFORD R. The role of personal beliefs and social influences as determinants of respirator use among construction painters. Scand J Work Environ Health 14 (1988) 239-245. The purpose of this study was to identify and rank potential determinants of respirator use among painters in the construction industry. As part of a health survey of union painters, 169 male spray painters were questioned about their own beliefs concerning the consequences of wearing cartridge respirators, as well as about the perceived attitudes of others in the workplace toward respirators. Intended respirator use was more strongly associated with beliefs than was past use. The most important beliefs concerned discomfort or inconvenience. Other determinants that were associated with respirator use were respirator availability, cigarette smoking, and social influences. It was concluded that the most effective intervention strategy to increase respirator use would be multidimensional and that efforts to change only a worker's beliefs may have limited success.
\end{abstract}

Key terms: attitudes, behavioral intentions, chemical cartridge respirators, cigarette smoking, respiratory protection programs, spray painting.

At a construction site, high rates of paint application and the lack of adequate ventilation can cause solvents and other paint components to reach toxic levels (12, 15). For construction painters, respirator programs are considered an important method with which to control these potentially toxic exposures. Previous epidemiologic studies of painters have reported a range of adverse health effects $(4,7,8,20)$. Moreover, a casereferent study of lung cancer among persons in the painting trades reported a fivefold excess risk of lung cancer for painters who did not wear a mask or respirator (18).

The worker's decision concerning when and whether to wear the respirator is a major influence on the degree of protection that can be achieved by respirators (14). However, previous surveys of construction painters (International Brotherhood of Painters and Allied Trades, unpublished) indicated that most workers do not wear appropriate respiratory protective equipment on a regular basis. We were interested in identifying some potential determinants of intended respirator use among painters in the construction trade. This information then might be useful in developing more effective intervention strategies to reduce painters' exposures.

To identify and measure potential determinants of intended respirator use, we relied, in part, on a theory

\footnotetext{
1 Occupational Health Program, Harvard School of Public Health, Boston, MA, United States.

2 International Brotherhood of Painters and Allied Trades, Washington DC, United States.
}

Reprint requests to: Dr E Baker, National Institute for Occupational Safety and Health, Centers for Disease Control, Atlanta, GA 30333, USA. which was developed from studies on the relationship between attitudes and other social behaviors $(2,5)$. According to this theory, a person's intention to behave in a particular manner is determined by his attitude toward the behavior and by what he perceives is the accepted social norm, and his attitude is a function of his beliefs about the consequences of the behavior. The prevailing view among psychologists that attitudes can predict and cause behavior has lead to the increased application of attitude models in specific settings (3). However, we are not aware of any previous application of such theories with regard to respirator use.

Focus was placed on the following three general areas which may influence the frequency of respirator use among construction painters: (i) the strength of beliefs about the benefits of respirator use; (ii) the strength of beliefs about the drawbacks of respirator use; and (iii) external and social factors, including the perceived attitudes of employers and fellow workers. Since the determinants of respirator use may vary by the type of respirator, focus was specifically placed on chemical cartridge respirators. The context was spray painting at work, since this is the situation in which paint application rates and exposures are likely to be the highest. Painters were asked about wearing respirators all of the time while spray painting, ie, continuous instead of intermittent respirator use.

A primary goal of this research was to evaluate the relative importance of several potential determinants of past and intended respirator use among spray painters. Such information may have implications for proposed respiratory protection programs in other occupational settings. 


\section{Subjects and methods}

\section{Study population}

The study participants were current members of two local union affiliates, located in Fort Worth, Texas, and Memphis, Tennessee, of the International Brotherhood of Painters and Allied Trades (IBPAT). All had agreed to participate in a separate study aimed at evaluating the effectiveness of an IBPAT-developed training program. Recruitment of the study participants was conducted by union employees. All current members of the two local unions, identified from a computerized list of current members, were sent a letter explaining the study and offering free health examinations; the letter was followed by a telephone call. Only regular and apprentice IBPAT members who attended the 1984 health screening were included in this study.

A total of 663 regular and apprentice union members were identified in the two local unions; $37.1 \%$ participated in the health screening. Of these 246 regular and apprentice union members, 169 were male painters who had spray painted in the past and who intended to spray paint during the next year. These male spray painters constituted the population for this analysis. The spray painters ranged in age from 20 to 67 (mean 38.5) years and had worked as painters for less than 1 to 48 (mean 16.6) years.

Information about age, years in union, and hours contributed to the pension fund in 1983 and 1984, for eligible IBPAT members, was obtained from computerized union records. Screening participants and nonparticipants had similar mean ages $(40.8$ versus 41.7 years, $P=0.42$ ) and years since joining the union (11.4 versus 10.8 years, $\mathrm{P}=0.47$ ). Compared to the nonparticipants, the screening participants had contributed more mean hours to the pension fund in 1983 (1 047.3 versus $901.7 \mathrm{~h}, \mathrm{P}=0.026$ ) and during the first six months of $1984(584.2$ versus $454.0 \mathrm{~h}, \mathrm{P}<0.001)$.

\section{Data collection}

At the time of the health examination, all the participants were asked to complete a self-administered questionnaire which covered their medical and occupational history. Later, trained interviewers (university staff or trainees) reviewed the entire questionnaire with the participants for completeness and accuracy. In rare instances, the entire questionnaire was administered by the interviewer. Finally, questionnaires were rechecked for completeness and accuracy at the time the participants finished the health examination.

Painters were asked how frequently they wore chemical cartridge respirators over the entire time they had worked and how frequently they intended to wear a chemical cartridge respirator while spray painting over the next year. Use was measured as never, sometimes (less than $40 \%$ of the time), about half of the time (40 to $60 \%$ of the time), most of the time (60 to $90 \%$ of the time), and always (more than $90 \%$ of the time). The painters were also asked how often employers supplied cartridge respirators for their use while painting, and their responses fell into the same categories, ie, never, sometimes, about half the time, most of the time, or always.

The consequences of respirator use selected for the questionnaire were derived from interviews of painters from another local union, conversations with IBPAT officials, and the opinions of professionals in the field. Painters rated, on a scale from one to seven, the degree to which they agreed or disagreed with the statement, "If I continuously wore a cartridge respirator every time I spray painted, then," completed with each of the consequences listed in the appendix. The opinions of others toward the painter's wearing of the respirator were measured as the perceived attitudes, measured on a seven-point scale ranging from very favorable to very unfavorable, of most union representatives, most coworkers, and most employers.

\section{Analyses}

Statistical analyses were conducted with the assistance of SPSSx (16) and SPSS-PC (17). Nonparametric statistics were frequently used because several variables had been measured on rank-ordered scales.

For descriptive statistics only, responses from the seven-point scale which corresponded to mildly agree, agree, and strongly agree were combined into one agree category. Similarly, responses from the seven-point scale which corresponded to mildly favorable, favorable, and very favorable were combined into one favorable category. For all analytical statistics, the original seven-point scales were maintained.

Spearman's rho, a nonparametric, rank-order correlation coefficient, was computed between all the responses to statements concerning the possible consequences of respirator use and the attitudes of others. Spearman's rho was also computed for each response and both past respirator use and intended use during the next year. Significance levels were based on a twotailed rest.

Ridit analysis (6) was used to compare the distribution of individuals by response categories between groups of painters defined by past and intended respirator use. Ridit analysis is a nonparametric technique which takes advantage of the natural ordering of categories without making any assumptions about the underlying distribution. This analysis was chosen because the variables being compared were measured on rank-ordered scales and their distributions were variable and often highly skewed.

By definition, the mean ridit for the reference group is 0.50 . The mean ridit for the comparison group can be interpreted as the probability that a randomly selected painter from the comparison group has a more extreme response than a randomly selected painter from the reference group. For example, a mean ridit 
greater than 0.50 , or a positive difference in mean ridits, would indicate that painters from the comparison group tend to have responses indicating more agreement with the statement than painters in the reference group. Conversely, a mean ridit of less than 0.50 , or a negative difference in mean ridits, would indicate that painters from the comparison group tend to have responses indicating less agreement. In the case of the perceived attitudes of others, a mean ridit greater than 0.50 would indicate more favorable attitudes, while a mean ridit of less than 0.50 would indicate less favorable attitudes. Standard errors of the mean ridits for the comparison groups were calculated with the formula of Selvin (13).

\section{Results}

\section{Personal characteristics}

The painters who wore a cartridge respirator all of the time and those who intended to do so in the next year were slightly younger than the painters in the other corresponding use groups (table 1). Painters who intended never to wear a cartridge respirator were significantly older $(P=0.04)$ than those who intended always to wear a cartridge respirator.

The frequency of past and intended use of cartridge respirators was lowest among the heavier smokers, who currently smoked more than 20 cigarettes per day (table 2). Painters who currently smoked cigarettes were asked to respond to the following statement: "If I continuously wore a cartridge respirator every time I spray painted, then I would not be able to smoke as often as I'd like." Compared to lighter smokers, a larger proportion of heavier smokers agreed with this statement $(60.0$ versus $37.5 \%, P=0.04)$.

\section{Relationship between beliefs, attitudes, and respirator use}

From a correlation matrix of all beliefs, the correlations were largest between beliefs about consequences of a similar nature, but they were smaller or nonexistent for unrelated consequences. For example, the correlation between agreement that the respirator would be uncomfortable and that it would make breathing difficult was 0.60 . However, the correlation between agreement that the respirator woud be uncomfortable and that the painter would be at lower risk of cancer was -0.04 .

Negative and statistically stable $(\mathrm{P}<0.001)$ correlations were measured between intended respirator use and beliefs that the respirator would be uncomfortable $(\mathrm{rho}=-0.45)$, would get in the way $(\mathrm{rho}=-0.40)$, would cause difficulty breathing $(\mathrm{rho}=-0.43)$, and would make the painter feel closed-in (rho $=-0.45$ ). Smaller negative correlations were measured between these same statements and reported past use, ranging from a rho of -0.21 to a rho of -0.26 .
Table 1. Frequency of past and intended future use of cartridge respirators among 169 spray painters.

\begin{tabular}{lcccc}
\hline $\begin{array}{l}\text { Frequency } \\
\text { of use }\end{array}$ & $\begin{array}{c}\text { Past use } \\
(\%)\end{array}$ & $\begin{array}{c}\text { Mean age } \\
\text { (years) }\end{array}$ & $\begin{array}{c}\text { Intended use } \\
(\%)\end{array}$ & $\begin{array}{c}\text { Mean age } \\
\text { (years) }\end{array}$ \\
\hline Never & 27.2 & 38.7 & 16.6 & 41.9 \\
Sometimes & 34.3 & 38.6 & 16.6 & 40.4 \\
About half & 10.1 & 40.9 & 7.7 & 37.3 \\
Most of the time & 17.2 & 39.3 & 22.5 & 39.4 \\
All the time & 11.2 & 34.5 & 36.7 & 35.9 \\
\hline Total & 100.0 & 38.5 & 100.0 & 38.5 \\
\hline
\end{tabular}

Table 2. Percentage of spray painters who never wore a respirator in the past, or who intend never to wear a respirator in the next year, by current smoking status.

\begin{tabular}{lccc}
\hline Smoking status & Number & $\begin{array}{c}\text { Never wore } \\
\text { in past } \\
(\%)\end{array}$ & $\begin{array}{c}\text { Intend never } \\
\text { to wear } \\
(\%)\end{array}$ \\
\hline Current smoker & & & \\
$>20$ cigarettes/d & 37 & 45.9 & 27.0 \\
$\leq 20$ cigarettes/d & 51 & 15.7 & 17.6 \\
Former smoker & 47 & 21.3 & 12.8 \\
Lifetime nonsmoker & 33 & 30.3 & 9.1 \\
\hline Total & 168 & 26.8 & 16.1 \\
\hline
\end{tabular}

Beliefs about various health consequences were less strongly correlated with intended and past use. The largest rank ordered correlation was between the belief that the painter would be better able to produce healthy children (rho $=0.30, P<0.001$, for intended use and rho $=0.19, P=0.015$, for past use). Social influences were correlated with past and intended respirator use in the hypothesized direction. The largest correlation with intended use was the belief that others would think that the painter was foolish (rho $=-0.32, \mathrm{P}<0.001$ ).

The correlation between past respirator use and intended use over the next year was 0.53 . Just as current beliefs may influence intended use, past use may influence current beliefs. Therefore, the correlations between the various determinants and past use may be confounded by intended use, and vice versa. In order to examine these associations more clearly, we grouped the painters on the basis of both their past and intended respirator use. For these subgroups, low use was defined as never or sometimes, and high use was defined as most of the time or always. Use for half of the time was not included in either definition to keep the groups as distinct as possible.

Three subgroups of painters were identified on the 'basis of different patterns of past and intended respirator use, ie, low past use/low intended use, low past use/high intended use, and high past use/high intended use. (Only two painters fell into a high past use/low intended use group; too few to enable meaningful comparisons.)

For this analysis, the reference group was defined as the low past use/high intended use group. Comparison group I was the low past/low intent group; this group had a similar pattern of past respirator use 
Table 3. Characteristics of painters grouped by past respirator use and intended respirator use.

\begin{tabular}{|c|c|c|c|c|c|c|c|c|}
\hline \multirow[t]{2}{*}{ Use group } & \multirow[t]{2}{*}{ Number } & \multicolumn{2}{|c|}{ Age (years) } & \multicolumn{2}{|c|}{$\begin{array}{l}\text { Years worked } \\
\text { as a painter }\end{array}$} & \multicolumn{2}{|c|}{$\begin{array}{l}\text { Weeks worked } \\
\text { last year with } \\
\text { solvents }\end{array}$} & \multirow{2}{*}{$\begin{array}{c}\text { Current } \\
\text { smokers } \\
(\%)\end{array}$} \\
\hline & & Mean & SD & Mean & SD & Mean & SD & \\
\hline $\begin{array}{l}\text { Low past/high } \\
\text { intent (Reference) }\end{array}$ & 41 & 36.8 & 10.8 & 15.3 & 9.8 & 31.3 & 14.6 & 43.9 \\
\hline $\begin{array}{l}\text { Low past/low intent } \\
\text { (Comparison I) }\end{array}$ & 50 & 40.6 & 12.3 & 18.0 & 11.6 & 25.6 & 18.0 & 58.0 \\
\hline $\begin{array}{l}\text { High past/high intent } \\
\text { (Comparison II) }\end{array}$ & 45 & 37.1 & 13.1 & 14.7 & 10.6 & 29.5 & 18.0 & 55.6 \\
\hline
\end{tabular}

Table 4. Association between responses to statements about the consequences of respirator use or attitudes of others and intended respirator use, controlled for past use - Comparison group 1 (low past/low intent). ${ }^{\text {a }}$

\begin{tabular}{|c|c|c|c|}
\hline \multirow[b]{2}{*}{ Consequence of use } & \multicolumn{3}{|c|}{ Association with intended use } \\
\hline & $\begin{array}{l}\text { Difference } \\
\text { in mean ridit }\end{array}$ & $\begin{array}{l}S E \text { of } \\
\text { mean ridit }\end{array}$ & P \\
\hline \multicolumn{4}{|l|}{ Discomfort } \\
\hline $\begin{array}{l}\text { Uncomfortable } \\
\text { Feel closed-in } \\
\text { Would get in the way } \\
\text { Difficulty breathing } \\
\text { Not able to talk }\end{array}$ & $\begin{array}{l}0.27 \\
0.21 \\
0.20 \\
0.19 \\
0.07\end{array}$ & $\begin{array}{l}0.060 \\
0.059 \\
0.060 \\
0.060 \\
0.060\end{array}$ & $\begin{array}{l}<0.001 \\
<0.001 \\
<0.001 \\
0.002 \\
0.24\end{array}$ \\
\hline \multicolumn{4}{|l|}{ Health-related benefits } \\
\hline $\begin{array}{l}\text { Less risk of accident } \\
\text { Produce healthy children } \\
\text { More mentally alert } \\
\text { Feel better after work } \\
\text { Would live longer } \\
\text { Less risk of cancer }\end{array}$ & $\begin{array}{l}-0.21 \\
-0.17 \\
-0.16 \\
-0.11 \\
-0.11 \\
-0.11\end{array}$ & $\begin{array}{l}0.060 \\
0.058 \\
0.059 \\
0.053 \\
0.055 \\
0.056\end{array}$ & $\begin{array}{r}<0.001 \\
0.004 \\
0.008 \\
0.047 \\
0.042 \\
0.048\end{array}$ \\
\hline \multicolumn{4}{|l|}{ Health-related risk } \\
\hline $\begin{array}{l}\text { More risk of heart attack } \\
\text { Effectiveness }\end{array}$ & 0.13 & 0.059 & 0.031 \\
\hline $\begin{array}{l}\text { Best type of protection } \\
\text { Lungs protected }\end{array}$ & $\begin{array}{l}-0.03 \\
-0.01\end{array}$ & $\begin{array}{l}0.057 \\
0.053\end{array}$ & $\begin{array}{l}0.58 \\
0.91\end{array}$ \\
\hline \multicolumn{4}{|l|}{ Social influences } \\
\hline Others think foolish & 0.15 & 0.056 & 0.009 \\
\hline \multicolumn{4}{|l|}{ Attitudes of others } \\
\hline $\begin{array}{l}\text { Most employers } \\
\text { Most fellow workers } \\
\text { Most union representatives }\end{array}$ & $\begin{array}{l}-0.09 \\
-0.09 \\
-0.04\end{array}$ & $\begin{array}{l}0.060 \\
0.057 \\
0.057\end{array}$ & $\begin{array}{l}0.12 \\
0.11 \\
0.52\end{array}$ \\
\hline
\end{tabular}

a Reference group: low past use/high intended use, with mean ridit $=0.50$.

as the reference group, but their use during the next year was to be less frequent. The comparison between the reference group and comparison group I examined the relationship between certain beliefs and perceived attitudes and intention to use respirators among a group with similar reported respirator use in the past.

Comparison group II was the high past/high intent group; this group had a similar pattern of intended respirator use during the next year as the reference group, but their past use had been more frequent. The comparison between the reference group and comparison group II examined the relationship between past respirator use and certain beliefs and attitudes among a group with similar intentions to use respirators.

The painters in the three groups differed slightly in mean age, mean number of years worked as a painter, mean number of weeks using solvents in the past year, and the proportion of current smokers (table 3), but none of these differences was statistically significant at alpha $=0.05$.

Ridit analysis was used to compare the distribution of responses between the subgroups. In this analysis, the measure of association is the difference of the mean ridit value for the comparison from the reference value of 0.50 . For comparison group I (lower intended use), the mean ridits for statements related to discomfort or inconvenience differed the most from the reference value (table 4). In comparison to the reference group, the painters with less intent to wear a respirator were more likely to agree with statements that the respirator would be uncomfortable, would make them feel closed-in, would get in the way, and would make breathing difficult. In addition these painters were less likely to agree with statements concerning various health benefits of use and more likely to agree that other people would think that they were foolish. Little difference was observed in agreement to statements concerning the general effectiveness of respirators. Painters in comparison group I (lower intended use) indicated slightly less favorable perceived attitudes for employers, fellow workers, and union representatives.

In contrast, painters in comparison group II (higher past use) had mean ridits close to the reference value of 0.50 for all consequences of respirator use, indicating little difference in agreement from that of the reference group (table 5). Thus, differences in past respirator use appeared to be unrelated to current beliefs about the consequences of respirator use. Painters in comparison group II (higher past use) indicated slightly more favorable attitudes on the part of others toward their use of respirators.

\section{Respirator availability and respirator use}

The question concerning intended respirator use during the next year stipulated, "if available." Although it is the employer's responsibility to provide respirators when needed, $39 \%$ of the painters stated that they own their own cartridge respirator. Less than half $(49.1 \%)$ of the painters stated that employers supplied cartridge respirators most of the time or always (table 6). The provision of respirators by employers was associated with past respirator use (rho $=0.46, \mathrm{P}<0.001)$, but it was associated less strongly with intended future use 
(rho $=0.22, \mathrm{P}=0.002$ ). Among the painters in the low past/high intent subgroups, $17.1 \%$ indicated that employers always provided respirators, compared to $16.0 \%$ in the low past/low intent group and $57.8 \%$ $(\mathbf{P}<0.0001)$ in the high past/high intent group.

\section{Discussion}

These data suggest that beliefs influence a painter's intention or motivation to wear a respirator. Among those studied, the most important beliefs concerned discomfort or inconvenience. Beliefs about potential health benefits were also related to increased intention to wear a respirator, but they appeared to be less important than beliefs about discomfort. Belief about the general effectiveness of chemical cartridge respirators were unrelated to intended respirator use.

This research also suggests that the perceived attitudes of others may be a more important determinant of respirator use than has been generally recognized and that the perceived attitudes of all persons in the workplace, not just the individual worker, should be considered.

Intentions are only partially predictive of behavior. In this study, the provision of respirators by employers was associated with past use of respirators. In addition, many painters who had seldom worn respirators in the past indicated that they would wear respirators more frequently if respirators were made available to them.

The possible association between cigarette smoking on the job and respirator nonuse may be intuitively obvious, but it has been largely ignored in the literature on respirators. Our results suggest that this association exists primarily among the heavier smokers.

Due to the number of painters included in this study, the statistical power to detect smaller associations between determinants and respirator use was relatively low, and the ability to control simultaneously for several factors through multivariate statistical techniques was severely limited.

The painters may have had difficulty in providing valid estimates of past or intended respirator use or in ranking the strength of their beliefs or attitudes. Moreover, the painters who participated in this study were not a random sample of all eligible painters in the local unions. For these reasons, the simple prevalence measures of various determinants may not be representative of the painters in this union.

However, the purpose of this research was to examine possible associations between certain determinants and intended respirator use, not to estimate the prevalence of either beliefs or use patterns among painters. To create bias in the measures of association between certain determinants and reported past or intended respirator use, in a direction other than toward the null value, such errors would need to be systematic rather than simply random.
Table 5. Association between responses to statements about the consequences of respirator use or attitudes of others and past respirator use, controlled for intended use - Comparison group II (high past/high intent). ${ }^{a}$

\begin{tabular}{lccc}
\hline & \multicolumn{3}{c}{ Association with past use } \\
\cline { 2 - 4 } Consequence of use & $\begin{array}{c}\text { Difference } \\
\text { in mean ridit }\end{array}$ & SE of \\
& & & $\mathrm{P}$ \\
\hline Discom ridit & \\
Uncomfortable & & & \\
Feel closed-in & 0.03 & 0.060 & 0.66 \\
Would get in the way & -0.06 & 0.055 & 0.31 \\
Difficulty breathing & 0.00 & 0.057 & 0.99 \\
Not able to talk & -0.02 & 0.059 & 0.76 \\
Health-related benefits & -0.03 & 0.061 & 0.66 \\
Less risk of accident & & & \\
Produce healthy children & -0.06 & 0.061 & 0.29 \\
More mentally alert & 0.01 & 0.056 & 0.82 \\
Feel better after work & -0.02 & 0.057 & 0.71 \\
Would live longer & -0.04 & 0.053 & 0.47 \\
Less risk of cancer & 0.00 & 0.051 & 0.93 \\
Health-related risk & 0.01 & 0.053 & 0.84 \\
More risk of heart attack & & & \\
Effectiveness & 0.00 & 0.056 & 0.99 \\
Best type of protection & & & \\
Lungs protected & 0.01 & 0.056 & 0.84 \\
Social influences & -0.01 & 0.054 & 0.89 \\
Others think foolish & & & \\
Attitudes of others & -0.01 & 0.051 & 0.80 \\
Most employers & & & \\
Most fellow workers & 0.09 & 0.060 & 0.13 \\
Most union representatives & 0.10 & 0.058 & 0.076 \\
\hline a & 0.11 & 0.053 & 0.029 \\
\hline
\end{tabular}

a Reference group: low past use/high intended use, with mean ridit $=0.50$.

Table 6. Percentage reporting frequent past or intended respirator use by degree of respirator availability.

\begin{tabular}{lccc}
\hline $\begin{array}{l}\text { Provision of } \\
\text { respirators } \\
\text { by employers }\end{array}$ & Number & $\begin{array}{c}\text { Past use } \\
\text { most or } \\
\text { always } \\
(\%)\end{array}$ & $\begin{array}{c}\text { Intended use } \\
\text { most or } \\
\text { always } \\
(\%)\end{array}$ \\
\hline Never & 37 & 8.1 & 40.5 \\
Sometimes & 40 & 20.0 & 55.0 \\
About half the time & 9 & 22.2 & 22.2 \\
Most of the time & 30 & 26.7 & 73.3 \\
Always & 53 & 52.8 & 73.6 \\
\hline Total & 169 & 28.4 & 59.2 \\
\hline
\end{tabular}

For example, it is possible that some painters reported beliefs according to their perceptions of the researchers' beliefs, even though the questionnaires were self-administered. For this type of error to be systematic, these same individuals would also need to misrepresent their respirator use in a similar manner. The belief that most obviously might be expected to be related to respirator use concerned the ability of the respirator to protect the lungs against harmful chemicals. If the painters answered the questions systematically as they thought they should, then the belief that the respirator would protect the lungs from harmful chemicals should have been associated with more frequent past and intended respirator use. In fact, neither this belief nor the belief that respirators were the best form of protection was observed to be associated with either past or intended respirator use. In other research on social behaviors, it has been shown 
that the correlation between a belief and a behavior is smail when the belief is not tied to the particular behavior (1). Therefore, it is not surprising that agreement with the general statement about the effectiveness of respirators was not associated with respirator use in this study.

The beliefs that influence respirator use may differ by workplace. It had been reported that many steel workers believe that the physical stress of wearing a respirator will put them at an increased risk of having a heart attack (10). In this population of painters, this belief was negatively associated with intended respirator use, but the association was small.

The psychological literature is rich in different theories to explain the complexities of human behavior, and many different theories could have been applied to this research question. Fishbein's model, well-supported by previous research, was chosen to provide a framework by which to identify and measure potential determinants of respirator use. Although personality factors, which are not included in this model of social behavior, also may influence respirator use, such factors would be expected to be more resistant to intervention efforts such as training and education.

Because the personality of the painter was not assessed, we could not address the question of whether painters who smoke and do not wear respirators possess a more general risk accepting or risk taking trait. However, the data suggest that the association between heavier smoking and less frequent use of respirators may be due to the fact that painters cannot smoke and wear a respirator at the same time. Previous research on the belief patterns of cigarette smokers suggests that most have only a superficial understanding of the health risks of smoking and that their beliefs about these risks have not been internalized (19). Most experts agree that adults continue to smoke primarily because they are physically addicted to nicotine. Few would argue against the merits of providing assistance to workers who would like to quit smoking. Such efforts may have beneficial effects on respirator use, even if smokers are able only to reduce their cigarette consumption.

Some beliefs may not be amenable to training efforts. The beliefs that were most strongly associated with respirator nonuse concerned discomfort, which is more likely to be a function of the respirator than the wearer. It has been suggested that beliefs about health risks and feelings of discomfort may be related, ie, that workers who experience discomfort from respirators may repress concerns about health risks (9) or that knowledge of the health risks may lead to a reduced perception of the respirator's discomfort (11). In this study beliefs about the negative consequences of respirator use were generally independent of beliefs about the potential long-term benefits of respirator use on health.

In the literature on the use of respirators in the workplace, considerable attention has been paid to the effect that claustrophobia, an abnormal fear of closed spaces, may have on respirator use. We did not measure the prevalence of claustrophobia, as medically defined, in the study population. However, it may be reasonable to estimate that the prevalence of clinically diagnosable claustrophia was close to zero, because this was an active work force (ie, "healthy worker effect"') and painters are often required to enter enclosed areas due to the nature of their work. Nevertheless, $27 \%$ of the painters agreed that wearing the respirator would make them feel closed-in or trapped. This observation suggests that the feeling of being closed-in is a relatively common, negative reaction to the wearing of a respirator, much like discomfort, which does not necessarily indicate that the worker is suffering from a psychological problem.

The results of this study support the view that respirator use is a social behavior and that the perceived attitudes of others in the workplace influence respirator use. Therefore, it may be useful to broaden the target audience of any training or intervention program to include supervisors, management personnel, and union representatives. A related issue may be the definition of respirator availability. The need to request respirators from employers, many of whom may be perceived as having unfavorable attitudes, may prevent some painters from using respirators. We measured a painter's perception of respirator availability, and this variable may not be the same as the provision of respirators only when requested. Clearly, ease of access to respirators is needed to encourage their use.

The factors which influence a painters's decision to wear a respirator are undoubtedly complex, and we were able to measure only a few potential determinants. The results of this research suggest that the most effective intervention strategy to increase respirator use would be multidimensional, focusing on several different determinants of respirator use. Training efforts which attempt to change the worker's beliefs may be useful, but alone may have limited success.

\section{Acknowledgments}

This investigation was supported by Public Health Service (PHS) grant number 1 RO3 CA41131-01, awarded by the National Cancer Institute, US Department of Health and Human Services (DHHS). Data collection was supported by PHS grant number 1 RO1 CA34919-01, awarded by the National Cancer Institute, DHHS, to the International Brotherhood of Painters and Allied Trades. During this investigation, Dr White was supported by a National Institute of Environmental Health Sciences National Research Service Award 5T32ES07069 from the Harvard School of Public Health.

Dr L D'Altroy provided valuable guidance in the initial design of this study, and Drs J Bailar, E Eisen, 
and $\mathrm{R}$ Monson provided thoughtful comment and criticism on earlier drafts. The authors wish to thank the members of IBPAT Locals 49 and 318 for their cooperation in participating in this study and the staff and trainees of the Harvard Occupational Health Program for their assistance with the data collection.

\section{References}

1. Ajzen I, Fishbein M. Attitude-behavior relations: A theoretical analysis and review of empirical research. Psychol Bull 84 (1977) 888-918.

2. Ajzen I, Fishbein M. Understanding attitudes and predicting social behavior. Prentice-Hall, Inc, Englewood Cliffs, NJ 1980.

3. Cialdini RB, Petty RE, Cacioppo JT. Attitude and attitude change. Annu Rev Psychol 32 (1981) 357-404.

4. Elofsson S-A, Gamberale F, Hindmarsh T, Iregren A, Isaksson A, Johnsson I, Knave B, Lydahl E, Mindus P, Persson HE, Philipson B, Steby M, Struwe G, Söderman E, Wennberg A, Widén L. Exposure to organic soivents: A cross-sectional epidemiologic investigation on occupationally exposed car and industrial spray painters with special reference to the nervous system. Scand J Work Environ Health 6 (1980) 239-273.

5. Fishbein M, Ajzen I. Belief, attitude, intention and behavior: An introduction to theory and research. Addison-Wesley, Reading, MA 1975.

6. Fleiss JL. Statistical methods for rates and proportions. John Wiley \& Sons, New York, NY 1981, pp 150-159.

7. Hänninen $\mathbf{H}$, Eskelinen $L$, Husman $K$, Nurminen $M$. Behavioral effects of long-term exposure to a mixture of organic solvents. Scand J Work Environ Health 2 (1976) 240-255

8. Joint Programme Committee. Solvents in the work environment: Survey and analysis of needs for research. The Swedish Work Environment Fund, Stockholm 1980.

9. Morgan WP. Psychological problems associated with the wearing of industrial respirators: A review. Am Ind Hyg Assoc J 44 (1983) 671-676.

10. O'Brien M-W. Don't forget your muzzle: The respirator wearer's perspective. In: National Institute for Occupational Safety and Health. Proceedings from the NIOSH International Respirator Research Workshop, Morgantown, WV 1980, pp 15-26.

11. Pritchard JA. A guide to industrial respiratory protection. US Department of Health, Education and Welfare, National Institute for Occupational Safety and Health, Cincinnati OH 1976. (DHEW publication no (NIOSH) 76-189).

12. Ringen $\mathrm{K}$. Health hazards among painters. In: Englund A, Ringen K, Mehlman MA, ed. Occupational health hazards of solvents. Princeton Scientific Publishers Inc, Princeton, NJ 1982, pp 111-138. (Advances in modern environmental toxicology volume II).

13. Selvin S. A further note on the interpretation of ridit analysis. Am J Epidemiol 105 (1977) 16-20.

14. Snith TJ, Ferrell WC, Varner MO, Putnam RD. Inhalation exposure of cadmium workers: Effects of respirator usage. Am Ind Hyg Assoc J 41 (1980) 624-629.

15. Snashall DC. The construction industry. In: Harrington JM, ed. Recent advances in occupational health. Churchill Livingstone, Edinburgh 1984, pp $29-43$.

16. SPSS Inc. SPSSx user's guide. McGraw-Hill, New York, NY 1983.

17. SPSS Inc, Norusis MJ. SPSS/PC for the IBM PC/XT. SPSS Inc, Chicago, IL 1984.

18. Stockwell HG, Matanoski GM. A case-control study of lung cancer in painters. J Occup Med 27 (1985) 125126.

19. Warner KE. Selling smoke: Cigarette advertising and public health. American Public Health Association, Washington DC 1986.

20. White MC, Baker EL. Measures of respiratory illness among construction painters. Br J Ind Med (in press).

Received for publication: 20 March 1987

\section{Appendix}

\section{Wording used in the questionnaire for the consequences of wearing a chemical cartridge respirator when spray painting}

\section{Consequence}

The respirator would get in the way of my work.

I would feel better after work.

80.8

I would be more mentally alert at work (no dizziness or lightheadedness). 